\title{
Rolling Characteristics of New Compact Multi-reduction Mill*
}

\author{
By Kiyoto MIYASAKA,** Seiji KOIDE,*** Hiroyuki SHIOZAKI,*4 \\ Hiroyasu YAMAMOTO,*5 Teruo IURA,*6 Takao KAWANAMI*7 \\ and Akihiro TANAKA*8
}

\section{Synopsis}

Increasing the rolling reduction in thickness in one mill stand contributes to realize a compact mill line and less initial and running cost.

For this purpose many studies about the effect of the work roll diameter in case of conventional mill were tried out and it was recognized that the maximum rolling reduction per stand is about $45 \sim 55 \%$ at most.

In order to achieve the high reduction over $70 \%$ in one cold rolling stand, "The three-gap rolling method"" has been investigated. This New Compact Multi-Reduction Mill (NCM) consists of four work rolls arranged vertically in one housing and the strip is threaded through three roll gaps.

The practical stable rolling condition has been ascomplished on a test mill by regulating the tension, roll speed difference, rolling force, etc. Such rolling characteristics as the number of work rolls to be driven, the conditions to realize the optimum inter-gap tensions, and the position of the neutral points have been investigated theoretically. Further the rolling characteristics such as rolling force, torque, tensions, forward slip, rolling energy, and the optimum rolling conditions have been investigated experimentally.

The new compact multi-reduction mill enables the high reduction over $70 \%$ in one stand and gives sound strip surfaces by applying improved lubrication.

Finally the possibility of practical applications for tandem cold mills and reversing cold mills are discussed.

Key words: Cold rolling; high rolling reduction; multi-reduction mill; rolling characteristics; different roll speed rolling.

\section{Introduction}

In recent years, there has been an ever increasing demand for the high reduction in thickness in a single stand of rolling mill. A high reduction mill realizes a compact mill line with less initial and running cost. It is also possible for the high reduction mill to increase the entering strip thickness or decrease the number of passes.

Many studies for decreasing the rolling force have been made to get higher reduction in thickness in a single stand. For example, work rolls of much smaller diameter were adopted or the method giving different peripheral velocities to work rolls (the different roll speed rolling) was attempted.

As a result, it has proved that the maximum reduction per one stand is from 45 to $55 \%$ at most.

In order to achieve a high reduction over $70 \%$ in one cold rolling stand, Nippon Steel Corporation, Ishikawajima-Harima Heavy Industries Co., Ltd. (IHI), and Toshiba Corporation have developed a new compact multi-reduction mill (NCM) having three passes in one stand.

The present paper explains the necessity for the development of this mill and the basic rolling characteristics to get higher rolling reduction, to realize the stable rolling, etc.

\section{History of the Development of Higher Reduc- tion Mill}

\section{Maximum Rolling Reduction per Pass}

In conventional mill, to obtain higher rolling reduction, many trials have been carried out as shown in Fig. 1.

One method of getting higher reduction is to adopt the work rolls with smaller diameters. The other method is a different roll speed rolling. For further increase of rolling reduction in thickness, a mill with different diameter work rolls is favorable in regard to equivalent roll diameter and roll torque. It was recognized, however, that the maximum rolling reduction per one pass is from 45 to $55 \%$ at most.

\section{Multi-reduction Mill Having Work Rolls with Ex- tremely Different Diameters}

For much higher reduction, a rolling mill having multi-pass in one stand is effective. Figure 2 shows the conventional multi-reduction mills which have achieved the maximum reduction of $60 \sim 75 \%$. (CBS mill: contact bend stretch mill, V-mill: $\mathrm{V}$ form mill, TRM: tri-star roll mill)

The common feature of these mills is to use one

* Based on the paper presented to the 36th Japanese Joint Conference for the Technology of Plasticity, October 1985, Paper Nos. 120-128, The Japan Society for the Technology of Plasticity. Manuscript received on August 28, 1987; accepted in the final form on January 14, 1988. (C) 1988 ISIJ

** Rolling Mill Engineering Department, Ishikawajima-Harima Heavy Industries Co., Ltd., Shin-nakahara-cho, Isogo-ku, Yokohama 235.

*** Research Institute, Ishikawajima-Harima Heavy Industries Co., Ltd., Shin-nakahara-cho, Isogo-ku, Yokohama 235.

*4 Developing Department, Rolling Mill \& Press Division, Ishikawajima-Harima Heavy Industries Co., Ltd., Shin-nakahara-cho, Isogo-ku, Yokohama 235.

*5 R \& D Laboratories-III, Nippon Steel Corporation, Edamitsu, Yahatahigashi-ku, Kitakyushu 805.

*6 Formerly R \& D Laboratories-III, Nippon Steel Corporation. Now at Hikari Technical Laboratories, Hikari Works, Nippon Steel Corporation, Oaza Shimada, Hikari 734.

*7 Formerly R \& D Laboratories-III, Nippon Steel Corporation. Now at Department of Mechanical Engineering, Kanazawa Institute of Technology, Nonoichi-machi, Kanazawa 921.

*8 Metal Production Engineering Department, Toshiba Corporation, Shin-sugita-cho, Isogo-ku, Yokohama 235. 


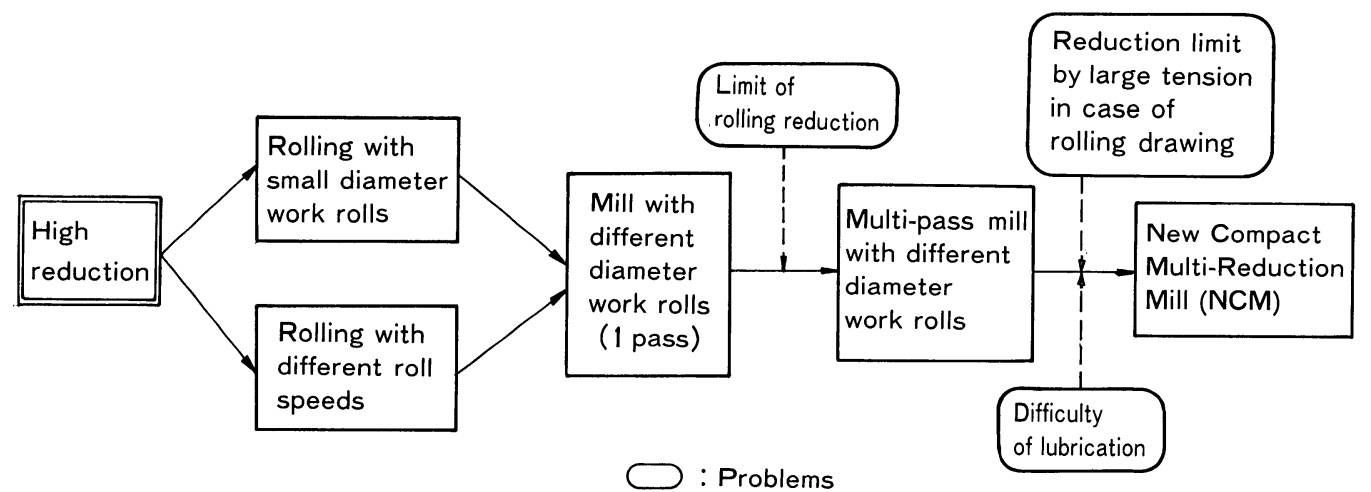

Fig. 1. Development of high reduction mill (Cold rolling).

\begin{tabular}{|c|c|}
\hline Schematic diagram & Example of Experiments \\
\hline CBS mill & $\begin{array}{l}\text { According to bibliography } \\
\text { Reduction : } 60 \% \\
\text { Roll dia. } \# 1,2 \cdots \phi 100 \\
\quad \# 3 \cdots \phi 8.64 \\
\text { Strip thickness } 0.5 \mathrm{~mm} \\
\text { Strip width } \quad 50 \mathrm{~mm}\end{array}$ \\
\hline$\overline{=}$ & $\begin{array}{l}\text { According to data of IHI } \\
\text { Reduction : over } 70 \% \\
\text { Roll dia. } \# 1,2 \cdots \phi 100 \\
\qquad 3 \cdots \phi 30 \\
\text { Strip thickness } 0.4 \mathrm{~mm} \\
\text { Strip width } \quad 50 \mathrm{~mm}\end{array}$ \\
\hline TRM & 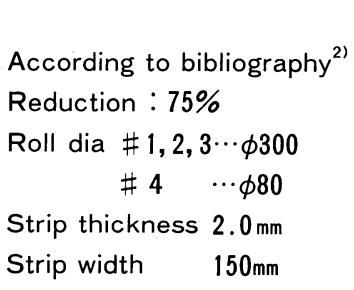 \\
\hline
\end{tabular}

The middle roll with a smallest diameter is not driven. Mark $\bullet$ indicates neutral points.

Fig. 2. Multi-reduction mill.

work roll having an extremely small diameter. The poor lubrication around the smallest roll and the resulting temperature elevation of small work roll, however, are the drawback for the application to high production line.

\section{Features of NCM}

On the other hand, NPV mill (continuous rolling drawing mill in USSR) which has the larger work rolls with the equal diameters was proposed (Fig. $3(\mathrm{a})$ ). In this mill the roll speeds increase toward the delivery pass, so that the strip is rolled by different roll speeds at each pass. As this method keeps the peripheral roll speed of the higher speed roll side and the out-going strip speed equal at each pass, the exit strip tension becomes quite high to restrict the total rolling reduction.

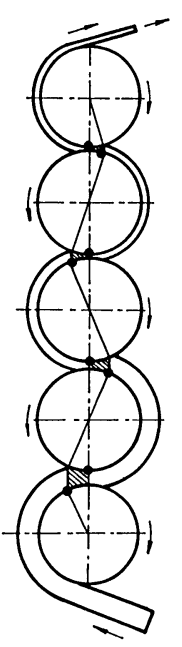

(a) $\mathrm{NPV}^{3)}$

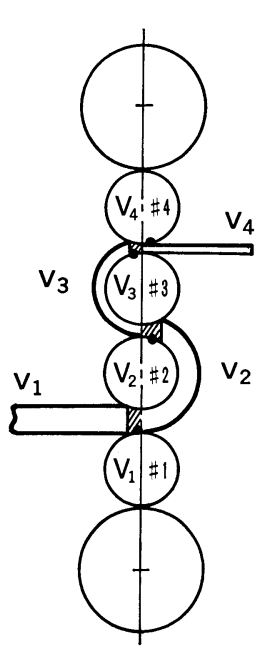

(b) NCM

\section{- Neutral point \\ $V_{i}$ : Roll peripheral speed $\quad v_{i}:$ Strip speed $i=1,2,3,4$}

Fig. 3. Comparison of NGM with NPV.

A new type of multi-reduction mill named NGM described here has been developed as an ideal mill which overcomes the disadvantages of conventional multi-reduction mills. The NCM mill has four work rolls and three rolling gaps as is shown in Fig. 3(b). This mill is characterized by the speed difference between the roll and strip. The roll peripheral speed $V_{i}$ and strip speed $v_{i}$ are generally set up as $V_{i}>v_{i}$. (In case of NPV rolling in Fig. 3(a), $V_{i}=v_{i}$ or $V_{1} \leqq$ $v_{1}$.) Consequently the neutral points in each pass can exist anywhere, so that the strip tensions between each gap can be determined to the practical range. Figure 4 shows a comparison of strip tension level between NCM and three pass NPV. The target reduction of NCM was settled to be $70 \%$.

The NCM mill has the following advantages:

(1) The strip can be rolled at three gaps by the same rolling force as that of conventional one pass rolling.

(2) Rolling force is lowered by the rolling with different roll speeds at each pass.

(3) The strip flatness is expected good because the rolling force gives no deflection to the intermediate 


\section{\#2 and \#3 rolls.}

A high rolling reduction can reduce the number of rolling stands. As shown in Fig. 5, a typical conventional tandem cold mill comprises five stands. The minimization of work roll diameter can eliminate one stand but not enough to decrease two rolling stands or more. After all it was concluded that NGM is the best for high reduction and for decreasing the number of rolling stands largely.

\section{Driving System}

Controlling the peripheral velocities of the four

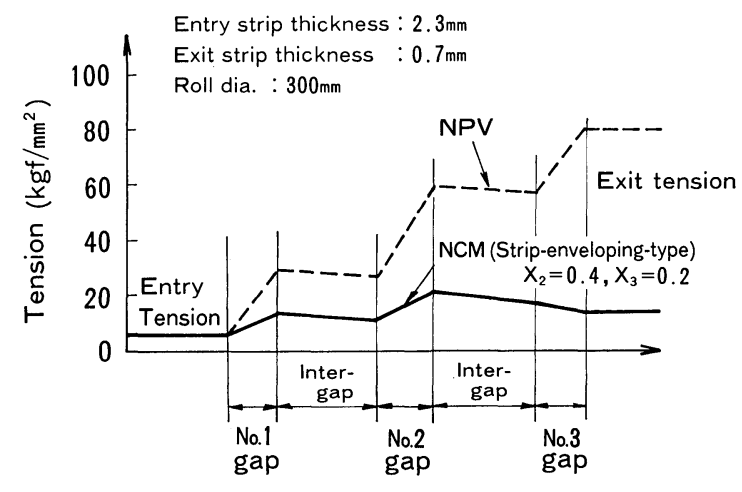

Fig. 4. Comparison of tension level between NCM and NPV.
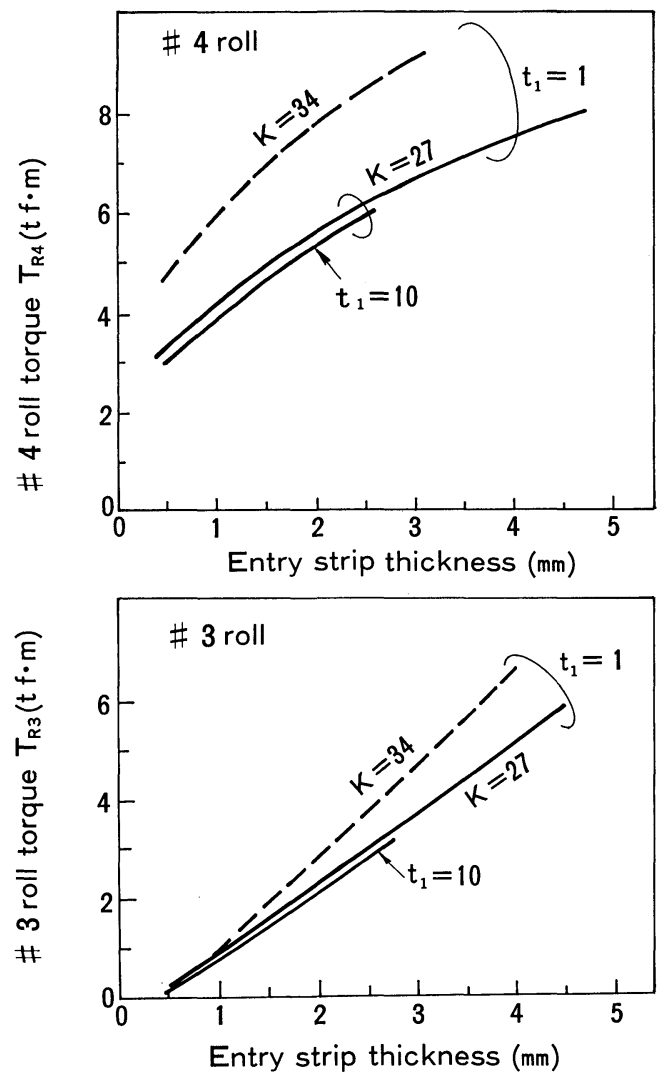

Roll diameter: $300 \mathrm{~mm}$

Strip width: $1000 \mathrm{~mm}$

$K$ : Initial flow stress $\left(\mathrm{kgf} / \mathrm{mm}^{2}\right)$

$t_{1}:$ Entry tension

$t_{2}=10 \mathrm{kgf} / \mathrm{mm}^{2}$ (Inter-gap tension between \#1 and \#2 passes)

$t_{3}=10 \mathrm{kgf} / \mathrm{mm}^{2}$ (Ditto between \#2 and \#3 passes) work rolls is a very important factor to realize the stable rolling. If the work rolls which need not be driven can apply to NCM, the driving system will be simplified. The possibility of applying non-driven rolls to NGM was investigated by the computer calculation based on the theory of different roll speed rolling. ${ }^{4,5)}$

Figure 6 shows the calculated results of the relationship between the entry strip thickness and the

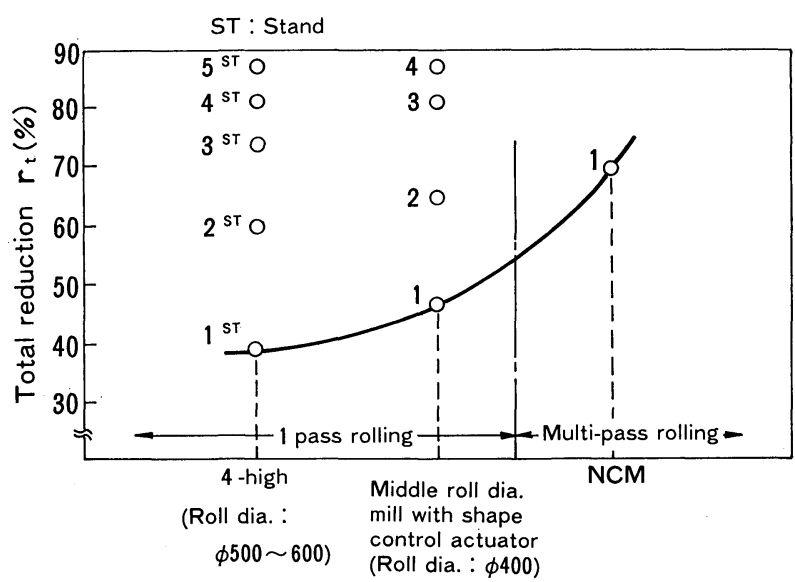

Fig. 5. Comparison of total rolling reductions with various kinds of mill types.
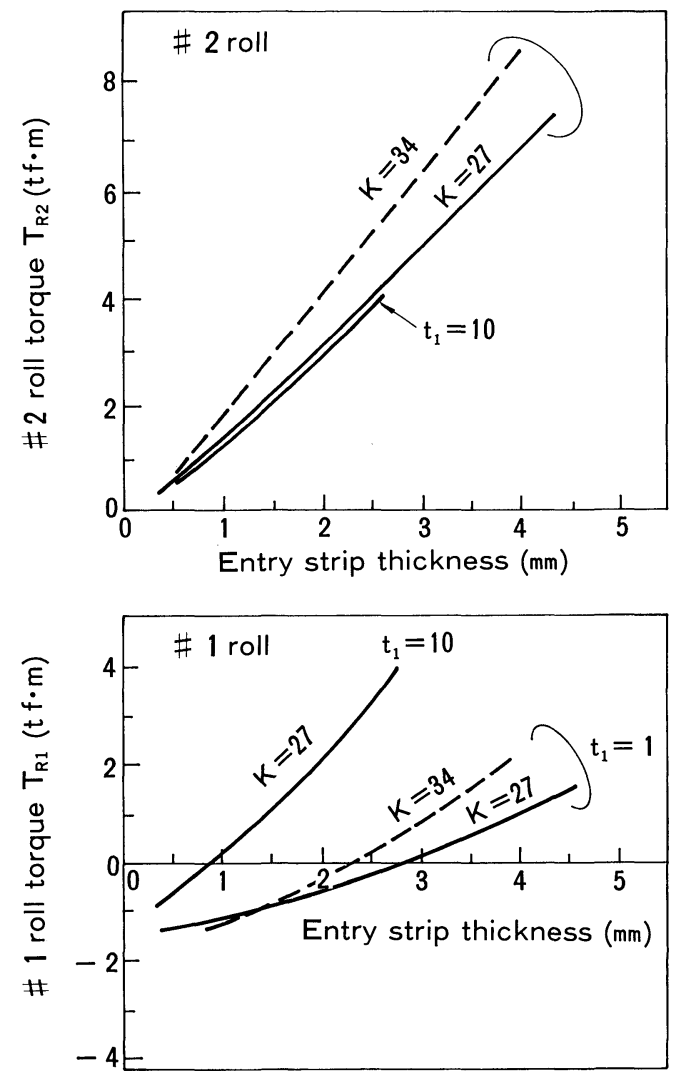

$t_{4}=15 \mathrm{kgf} / \mathrm{mm}^{2}$ (Exit tension)

$\mu_{1}=0.05$ (Friction coefficient at \#1 pass)

$\mu_{2}=0.06$ (Ditto at \#2 pass)

$\mu_{3}=0.07$ (Ditto at \#3 pass)

$r_{t}=70 \%$ (Total reduction)

All work rolls are driven.

Inter-gap tensions are kept constant.

Fig. 6. Roll torque (Calculation). 
torque of each work roll. The roll speed differences of each work roll are adjusted to keep the inter-gap strip tensions constant as presented in Fig. 6 .

In the range of the strip thickness over about $1 \mathrm{~mm}$ (which corresponds to the rolling at forestand or middle stand of TCM), \#1 roll torque is close to zero value, which means the possibility of applying idle rolling to \#1 roll. The adjustment of the inter-gap tensions makes \#1 roll torque zero for all range of strip thickness.

Figure 6 also suggests that the \#2 and \#3 roll can be non-driven for very thin strip under the thickness of about $0.5 \mathrm{~mm}$.

Experiments were conducted on a mill with \#1 roll idle, aiming mainly the high rolling reduction over $70 \%$ of ordinary mild steel at TCM.

\section{Experiment}

\section{NCM Test Mill}

As is shown in Fig. 7, NGM used for experimental rolling has two types of its configuration: (a) Stripenveloping type and (b) Strip-pulling-out type. Lubricants were supplied to each roll gap from strip entering side. By using type (b) which has two strippulling-out rolls, the inter-gap tensions can be measured easily by tension meters, so that the analytical calculations could be verified with the experimental results.

The test mill used was four-high whose roll diameters were close to those of practical use. Roll numbers are given serially toward delivery direction. Rolls \#2 to \#4 are driven to give difference of peripheral roll speeds each other. At the second pass the roll speed difference $X_{2}$ can be selected as listed in Table 1. At the third pass the roll speed difference $X_{3}$ can be changed continuously by individual motors. The $X_{2}$ and $X_{3}$ are defined in Table 1 .

\section{Rolling Characteristics of $\mathcal{N} C M$}

Table 1 also gives experimental conditions. The experimental data which will be presented hereinafter are mainly concerning about the strip-pulling-out type NCM.

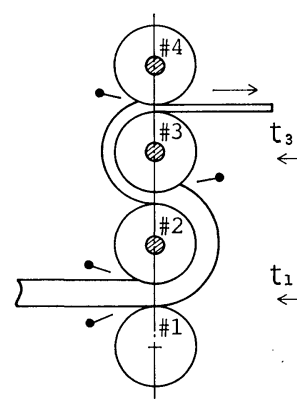

(a) Strip-enveloping type

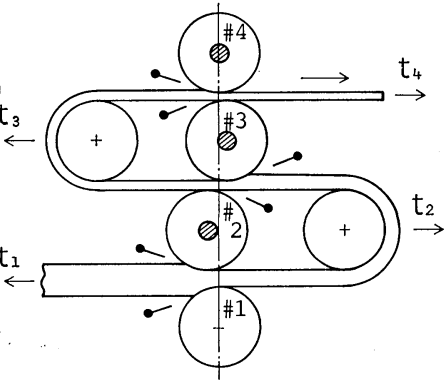

(b) Strip-pulling-out type

$$
\begin{aligned}
& i=1,2,3,4 \\
& \text { : Neutral point }
\end{aligned}
$$

$v_{i}:$ Strip speed $t_{i}:$ Strip tension

Fig. 7. NGM test mill.

\section{Rolling Force}

The rolling force of NCM shown in Fig. 8 is lower by $30 \sim 55 \%$ than that of conventional mill of one pass rolling.

The rolling force decreases with increasing the roll speed difference of the third pass $\left(X_{3}\right)$ under the same condition of the tension and the roll speed difference of the second pass $\left(X_{2}\right)$, or with increasing entry strip tension $\left(t_{1}\right)$ under the same condition of the exit strip tension $\left(t_{4}\right)$ and the roll speed difference of the second and the third pass. When the rougher surface rolls are used, the rolling force is higher than that by the bright rolls.

\section{Rolling Torque}

Figures 9 (a) and 9 (b) are the influence by the roll speed difference of each pass on the roll torque. The roll speed difference of the third pass gives greater

Table 1. Rolling condition.

\begin{tabular}{lll}
\hline & Work roll diameter & $300 \mathrm{~mm}$ \\
\cline { 2 - 3 } & Roll barrel length & $350 \mathrm{~mm}$ \\
\hline Main motor & $\begin{array}{l}150 \mathrm{~kW} \text { (for \#4 roll drive) } \\
300 \mathrm{~kW} \text { (for \#2, \#3 roll drive) }\end{array}$ \\
\cline { 2 - 3 } Moll speed difference & $\begin{array}{l}2 \mathrm{nd} \text { pass : } 0,0.11,0.24,0.35 \\
(i=2)\end{array}$ \\
& $X_{i}=\frac{V_{i+1}}{V_{i}}-1$ & $\begin{array}{l}3 \mathrm{rd} \text { pass : } 0 \sim 0.5 \\
(i=3)\end{array}$ \\
\cline { 2 - 3 } & Rolling speed & $\begin{array}{l}10 \mathrm{~m} / \mathrm{min} \text { (usual) } \\
200 \mathrm{~m} / \mathrm{min} \text { (maximum) }\end{array}$ \\
\hline \multirow{3}{*}{ Strip } & $\begin{array}{l}\text { Mild carbon steel (SPG) } \\
\text { Material }\end{array}$ & with phosphate treatment \\
\cline { 2 - 3 } & Thickness & $2.3 \mathrm{~mm}$ \\
\cline { 2 - 3 } & Width & $100 \mathrm{~mm}$ \\
\hline Lubrication & $6 \%$ emulsion of fat oil
\end{tabular}

\begin{tabular}{|c|c|c|c|c|}
\hline \multicolumn{2}{|c|}{ Tension $\left(\mathrm{kgf} / \mathrm{mm}^{2}\right)$} & \multicolumn{2}{|c|}{$\begin{array}{l}\text { Roll speed } \\
\text { difference }\end{array}$} & \multirow{2}{*}{ Symbol } \\
\cline { 1 - 4 } $\mathrm{t}_{1}$ & $\mathrm{t}_{4}$ & $\mathrm{X}_{2}$ & $\mathrm{X}_{3}$ & \\
\cline { 1 - 4 } 7.4 & 15.2 & 0.35 & 0.2 & - \\
\hline 7.5 & 15.2 & 0.35 & 0 & -- \\
\hline 3.2 & 14.9 & 0.35 & 0 & -- \\
\hline 5.0 & 16.0 & - & 0 & $-X$ \\
\hline
\end{tabular}

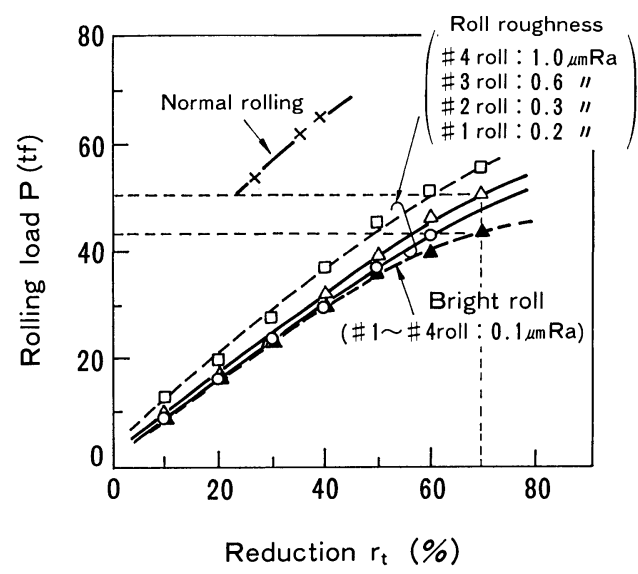

Fig. 8. Relationship between rolling load and reduction (Strip-pulling-out type). 


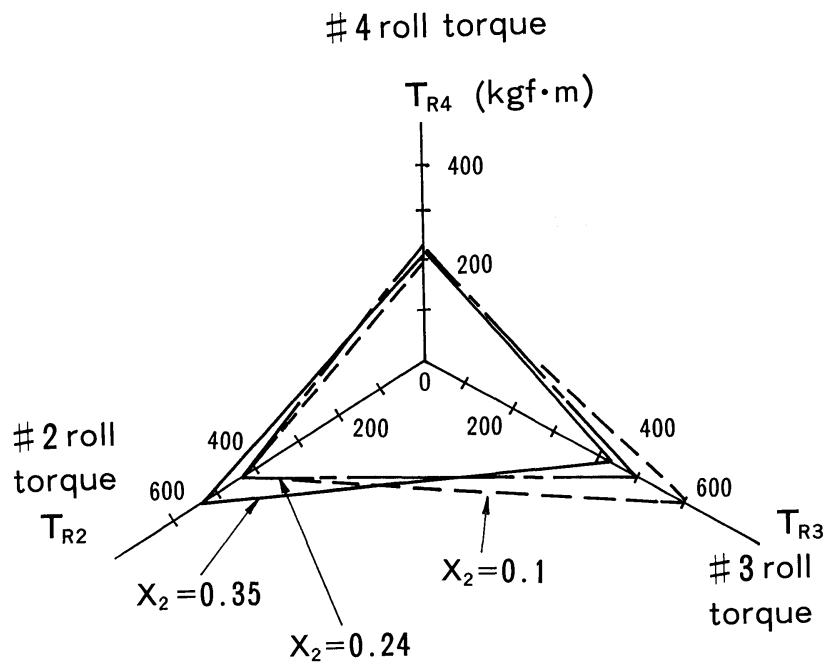

$\begin{array}{ll}t_{1}=7 \mathrm{kgf} / \mathrm{mm}^{2} & X_{3}=0.2 \\ t_{4}=14 \mathrm{kgf} / \mathrm{mm}^{2} & r_{t}=70 \% \\ \text { Bright roll: } \quad 0.1 \mu \mathrm{mRa} & \end{array}$

Fig. 9(a). Influence of roll speed difference at 2 nd pass on roll torque.

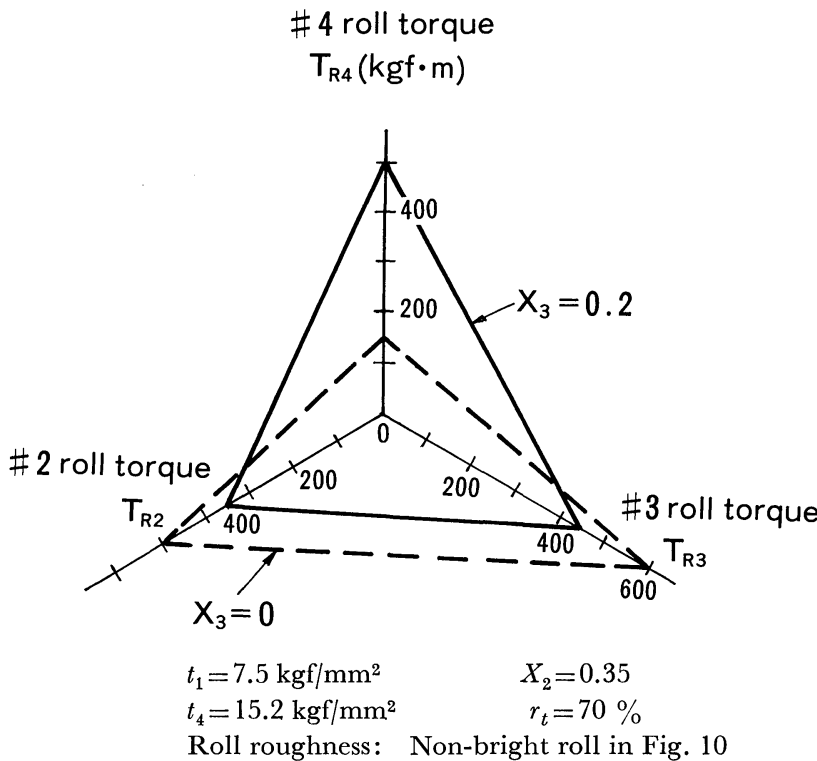

Fig. 9(b). Influence of roll speed difference at 3rd pass on roll torque.

influence on the roll torque than that of the second pass.

\section{Rolling Energy}

Figure 10 shows the relationship between the rolling reduction and the energy consumption. The rolling conditions except the roll surface roughness scarcely affects the rolling energy. The energy consumption in NGM is almost the same as the sum of three passes of conventional rolling.

\section{Inter-gap Tension}

The inter-gap tensions $t_{2}$ and $t_{3}$ should be kept properly for the stable rolling. Figure 11 shows the influence of the roll speed difference on the intergap tensions.

Figure 12 is the influence of the entry and exit tension. The roll speed difference at the second pass $\left(X_{2}\right)$ and the entry tension $\left(t_{1}\right)$ influence on the inter-

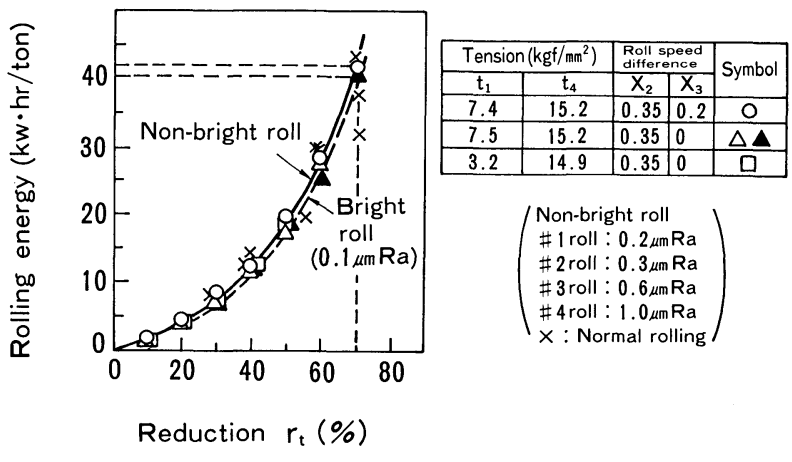

Fig. 10. Relationship between rolling energy and reduction (Strip-pulling-out type).

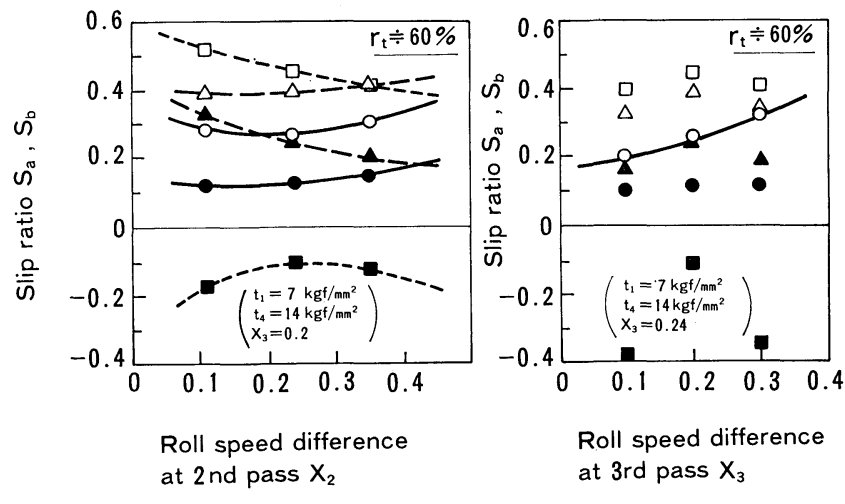

\begin{tabular}{|c|c|c|}
\hline \multicolumn{2}{|c|}{ Slip ratio } & \multirow{2}{*}{$\frac{\text { Symbol }}{-\mathrm{O}-}$} \\
\hline & $S_{3 a}$ & \\
\hline 3rd pass & $S_{3 b}$ & $-0-$ \\
\hline \multirow{2}{*}{ 2nd pass } & $S_{2 a}$ & $--\Delta--$ \\
\hline & $S_{2 b}$ & $--\Delta--$ \\
\hline \multirow{2}{*}{ 1st pass } & $S_{1 a}$ & - - - - - - - \\
\hline & $S_{1 b}$ & - . - . - - \\
\hline
\end{tabular}

Bright roll: $0.1 \mu \mathrm{m} \mathrm{Ra}$

Fig. 13. Influence of roll speed difference on slip ratio.

gap tensions, while the effect of the roll speed difference at the third pass $\left(X_{3}\right)$ and the delivery tension $\left(t_{4}\right)$ are relatively small.

Generally the inter-gap tensions were stable when the rolling conditions changed.

\section{Slip Ratio}

In case of NCM, the forward slip of the higher speed roll side at each gap is generally negative. In order to compare the absolute value of the slip between the strip and each roll, the slip ratios $S_{i a}$ and $S_{i b}$ are defined as follows.

$$
\begin{aligned}
S_{i a}= & \frac{V_{i+1}-\frac{1}{2}\left(v_{i}+v_{i+1}\right)}{V_{i+1}}, \\
S_{i b}= & \frac{V_{i}-\frac{1}{2}\left(v_{i}+v_{i+1}\right)}{V_{i}},
\end{aligned}
$$

where, $\quad V_{i}:$ roll speed

$v_{i}: \quad$ strip speed

Suffix $a$ : the higher speed roll side of the pass 

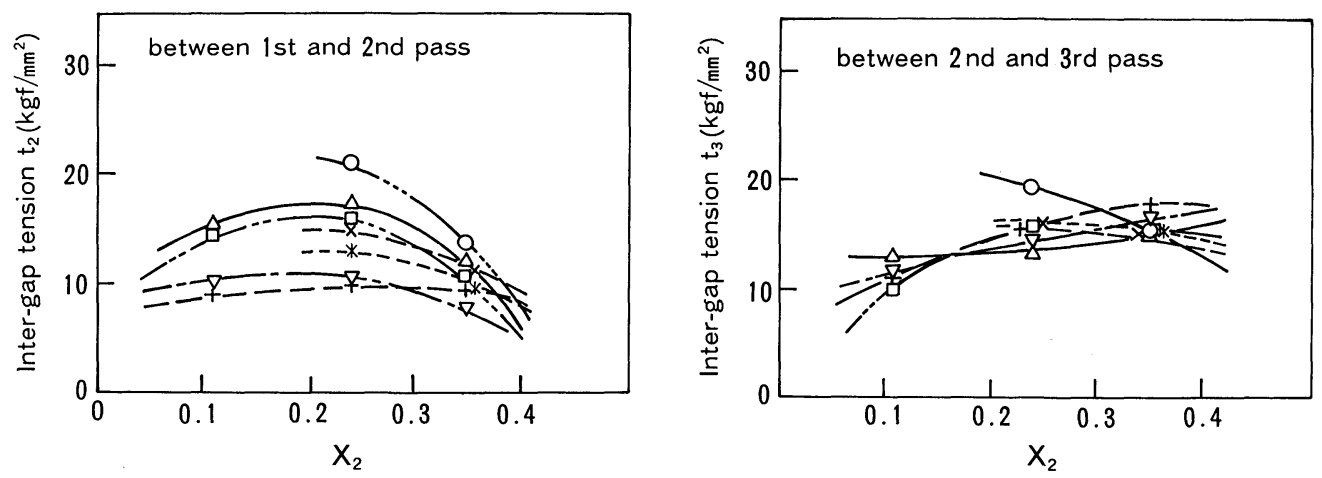

(a) Effect of roll speed difference at 2 nd pass : $X_{2} \quad\left(X_{3}=0.2\right)$
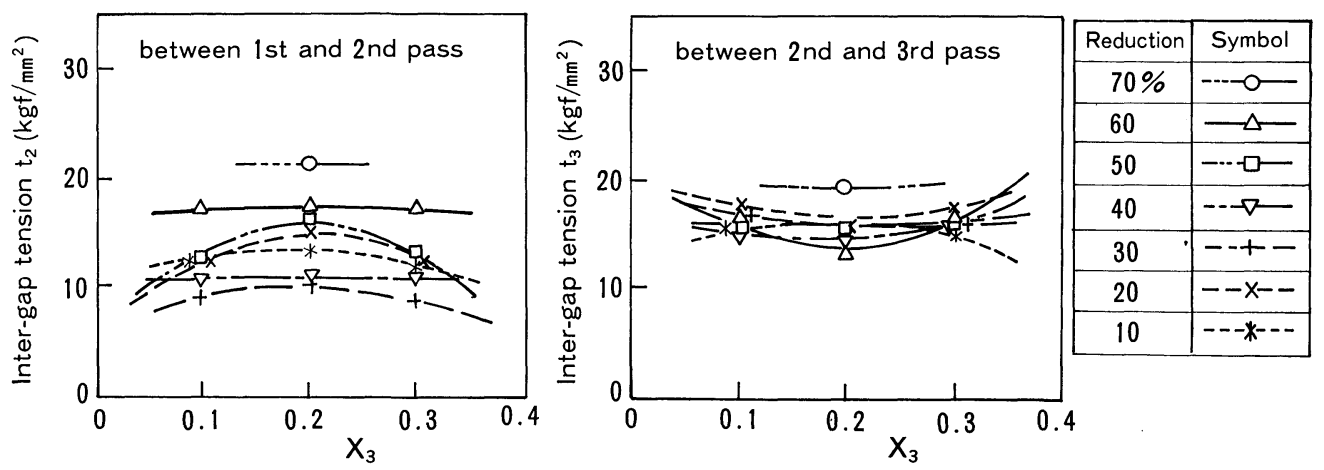

(b) Effect of roll speed difference at 3 rd pass: $X_{3} \quad\left(X_{2}=0.24\right)$

Fig. 11. Influence of roll speed difference on inter-gap tensions.
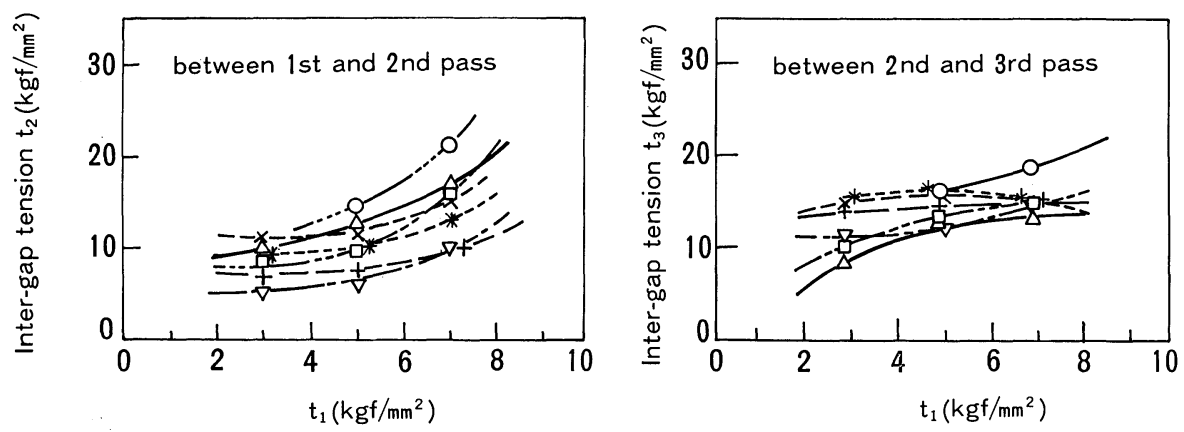

\begin{tabular}{|c|c|}
\hline Reduction & Symbol \\
\hline $70 \%$ & $--\infty$ \\
\hline 60 & $-\Delta$ \\
\hline 50 & $\cdots$ \\
\hline 40 & $--\nabla-$ \\
\hline 30 & -+- \\
\hline 20 & $--x-$ \\
\hline 10 & $---*-$ \\
\hline
\end{tabular}

(a) Effect of entry tension: $t_{1}$
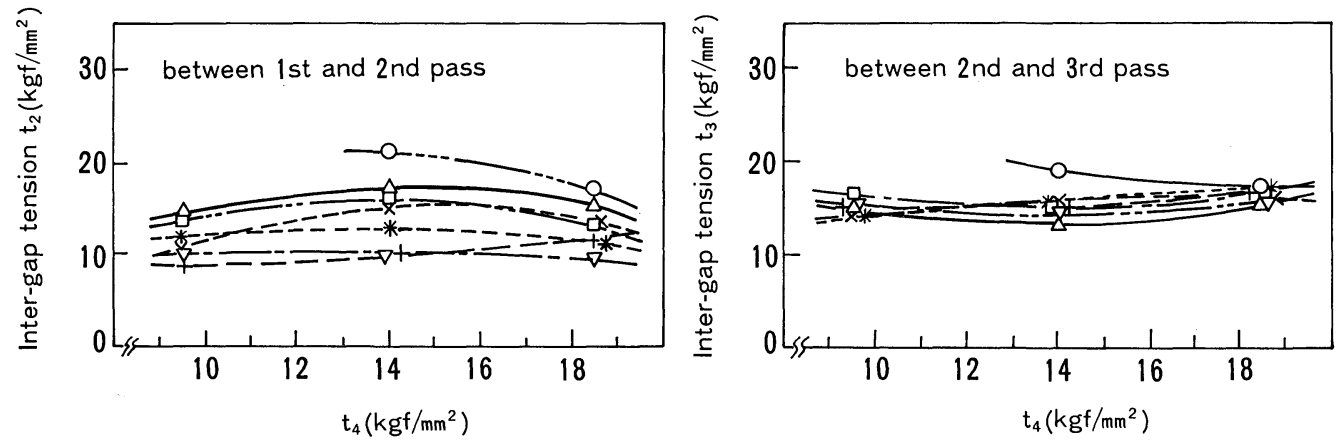

(b) Effect of exit tension: $t_{4}$

Fig. 12. Influence of entry and exit tensions on inter-gap tensions.

number " $i$ "

$b$ : the lower side of the pass number " $i$ ".

Figure 13 shows the changes of the slip ratio with the roll speed difference. The roll speed difference at the second pass gives an influence on $S_{2 b}$ and $S_{1 a}$, and the roll speed difference at the third pass on $S_{3 a}$. The entry or the exit tension hardly affected the slip ratios.

6. Comparison of Strip-pulling-out Type with Strip-
enveloping Type As already described, two types of NCM (strip- 
enveloping and strip-pulling-out type) were examined. The rolling characteristics of the strip-enveloping type are influenced by the friction between the inter-gap strip and each work roll. Experiments show that the rolling force or the consumption of the energy of both types are scarcely different but the roll torque and the forward slip are different.

Figure 14 shows each driving roll torque for both types. In the strip-enveloping type, the difference among the three work roll torques is smaller than that in case of the strip-pulling-out type. In the range of over $50 \%$ of the rolling reduction, each roll torque comes to the positive value, which contributes to a compact driving system.

On the other hand, the slip ratios of the stripenveloping type were smaller than that of the strippulling-out type.

\section{Influence of Rolling Speed}

For practical use, the rolling characteristics at higher speed rolling were examined, while so far it was around $10 \mathrm{~m} / \mathrm{min}$ in the basic experiments.

The rolling force and the rolling energy (Fig. 15) are scarcely affected by the rolling speed. Figure 16 shows the change of the inter-gap tensions with the rolling speed. Over the rolling speed of $100 \mathrm{~m} / \mathrm{min}$, the inter-gap tensions were stable.

\section{Optimum Rolling Condition}

The key points of NCM for the stable rolling are to keep the inter-gap tensions moderate and to minimize the slip ratios between the strip and each work roll by making the optimum roll speed differences. Figures 17 and 18 are drawn by using experimental results (Figs. 11 to 13) and analytical calculations. The optimum roll speed difference at the second pass $\left(X_{2}\right)$ increases with the rolling reduction, and at the third pass the value $X_{3}$ is available in the range of the dotted oblique line.

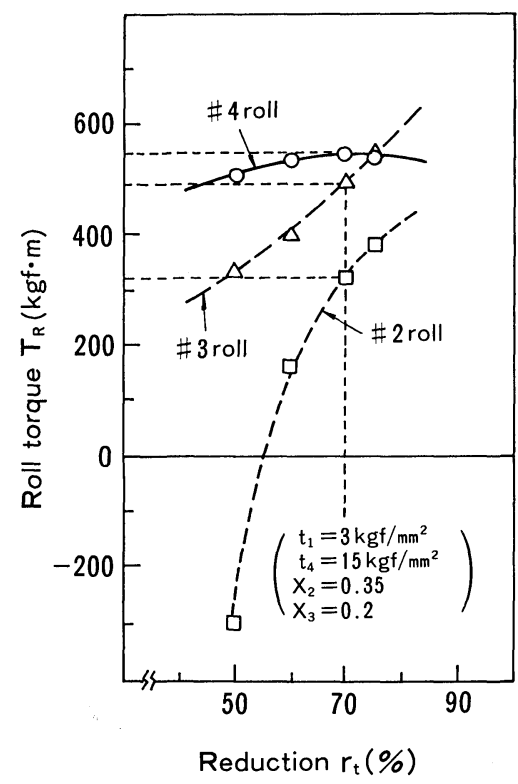

(a) Strip-pulling-out type

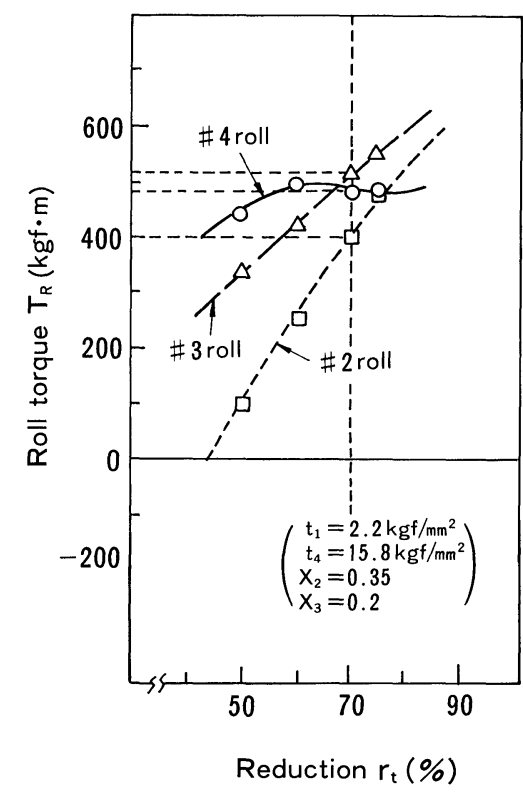

(b) Strip-enveloping type
Fig. 14. Relationship between roll torque and rolling reduction.

\section{Design for Practical Application}

\section{An Application to Tandem Cold Mill}

Figure 19 shows a configuration for practical application to an intermediate stand of tandem cold mill. In order to get simple NCM, the studies were made on conditions that all work roll diameters are the same and that the roll speed differences are so chosen as to keep all roll torques of the three driven work rolls equal (\#1 work roll is idle). Further the entry and delivery strip tensions $\left(t_{1}, t_{4}\right)$ of NCM and the roll speed differences $\left(X_{2}, X_{3}\right)$ are determined so that the intermediate tensions may be moderate. The assumed rolling process is a fully continuous type with the maximum strip width of $1800 \mathrm{~mm}$, and the maximum rolling speed of $1000 \mathrm{~m} / \mathrm{min}$. NGM gives the rolling reduction of $70 \%$ up to the entry strip thickness of $3.5 \mathrm{~mm}$. After all the work roll diameters of NGM were determined to be $600 \mathrm{~mm}$ based upon calculation.

This mill is so designed that the roll changing can

\begin{tabular}{|c|c|c|c|c|c|}
\hline Symbol & $r_{t}(\%)$ & $X_{2}$ & $X_{3}$ & $\begin{array}{c}\mathrm{t}_{2} \\
\left(\mathrm{~kg}^{2} / \mathrm{mm}^{2}\right)\end{array}$ & $\begin{array}{c}\mathrm{t}_{4} \\
\left(\mathrm{~kg}^{2} / \mathrm{mm}^{2}\right)\end{array}$ \\
\hline 0 & 70 & 0.35 & 0.22 & 7.0 & 15.7 \\
\hline$\square$ & 72 & 0.35 & 0.14 & 7.2 & 16.4 \\
\hline$\Delta$ & 71 & 0.35 & 0.03 & 7.2 & 15.3 \\
\hline
\end{tabular}

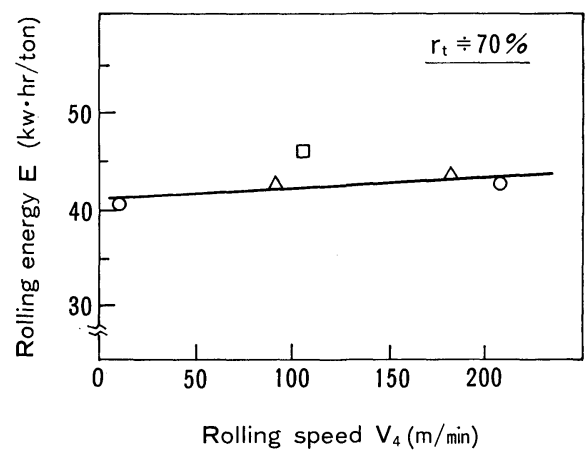

Fig. 15. Effect of rolling speed on rolling energy.

\begin{tabular}{|c|c|c|c|c|c|c|}
\hline \multicolumn{2}{|c|}{ Symbol } & \multirow{2}{*}{$r_{t}(\%)$} & \multirow{2}{*}{$X_{2}$} & \multirow{2}{*}{$X_{3}$} & \multirow{2}{*}{$\left.\begin{array}{c}t_{1} \\
\left(\mathrm{~kg} / / \mathrm{mm}^{2}\right.\end{array}\right)$} & \multirow{2}{*}{$\begin{array}{c}t_{4} \\
\left(\mathrm{kgt} / \mathrm{mm}^{2}\right)\end{array}$} \\
\hline$t_{2}$ & $t_{3}$ & & & & & \\
\hline 0 & - & 70 & 0.35 & 0.22 & 7.0 & 15.7 \\
\hline व & - & 72 & 0.35 & 0.14 & 7.2 & 16.4 \\
\hline$\Delta$ & $\Delta$ & 71 & 0.35 & 0.03 & 7.2 & 15.3 \\
\hline
\end{tabular}

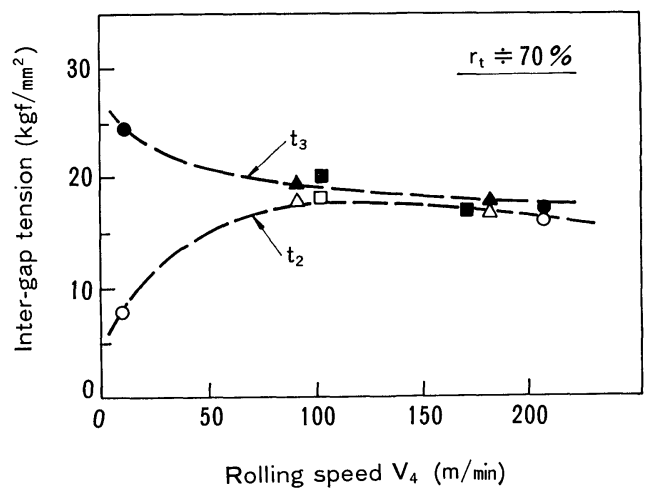

Fig. 16. Effect of rolling speed on inter-gap tensions. 


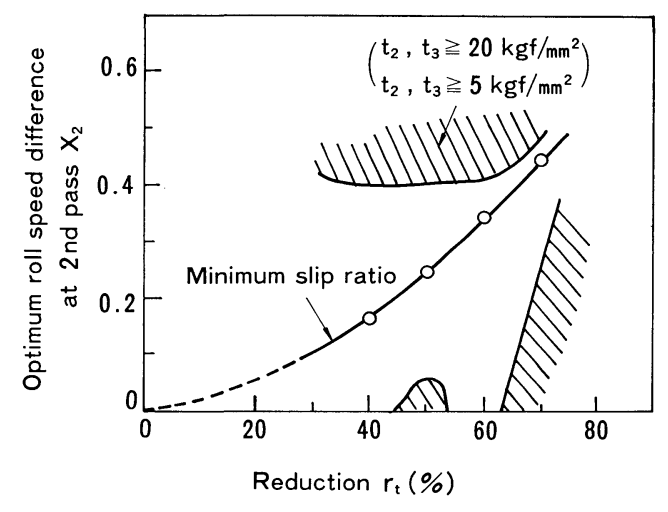

Fig. 17. Optimum roll speed difference at 2 nd pass.

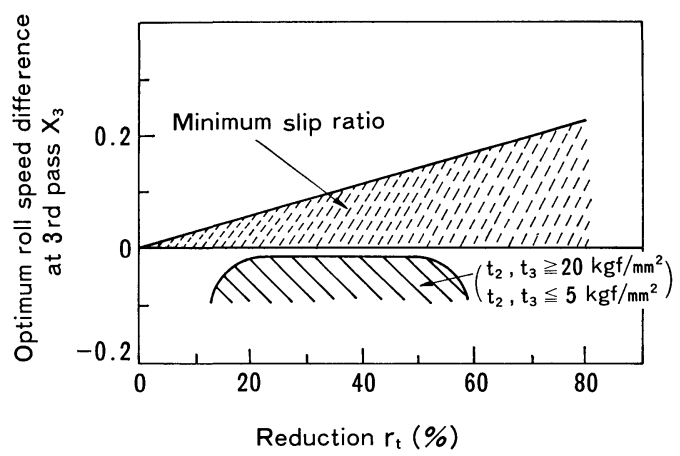

Fig. 18. Optimum roll speed difference at 3rd pass.

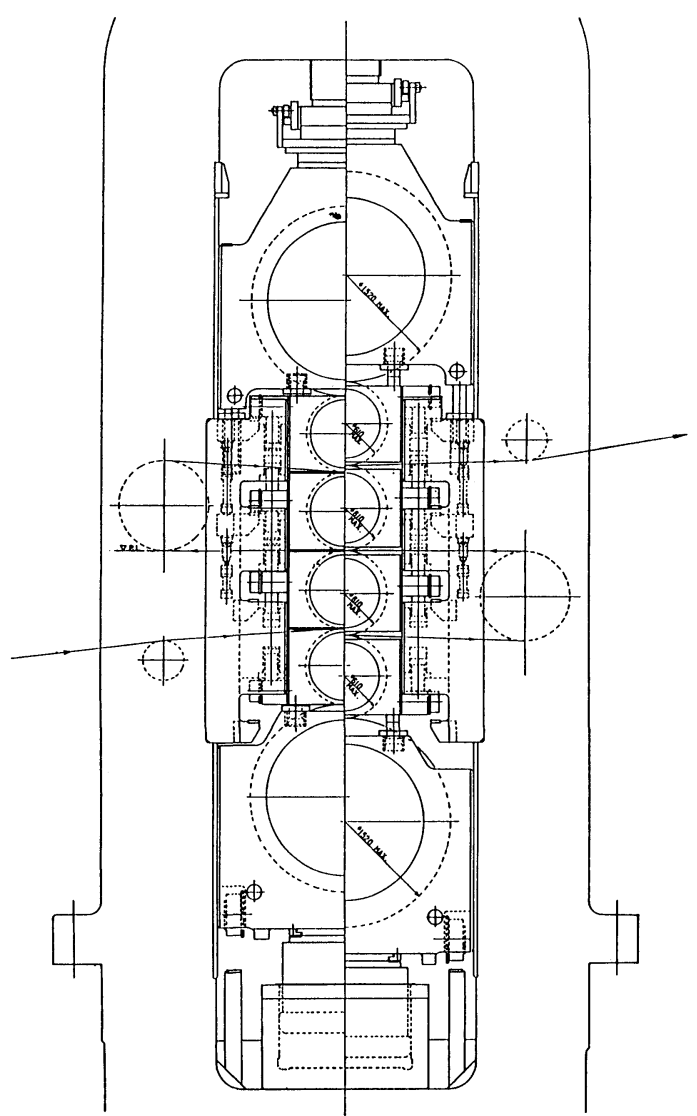

Fig. 19. An example of NCM configuration.

be operated without cutting the strip.

By employing NGM in a tandem mill, three stands can be replaced by one NCM stand as is shown in

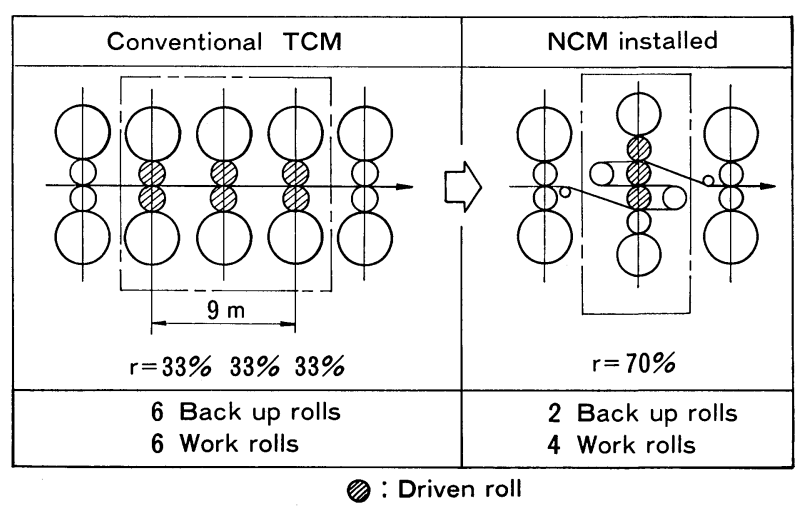

Fig. 20. An application of NGM to tandem cold mill.

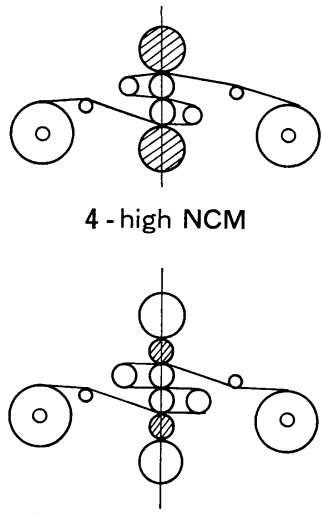

6 - high NCM

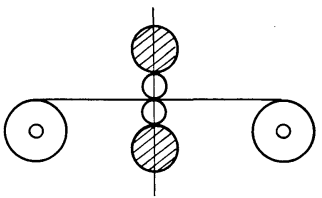

4 - high mill

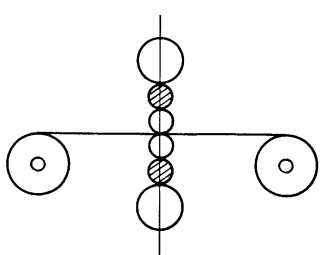

6 - high mill
: Driven roll

Fig. 21. An application to batch mill for thin hard material.

Fig. 20. According to the calculation of the pass schedule, the rolling forces of each stand is nearly equal. Obviously the low initial and running cost are realized by decreasing the number of the work and back up rolls.

\section{An Application to Batch Mill}

On the other hand, for very thin strip, \#2 and \#3 rolls can be non-driven rolls as mentioned in Chap. III. Figure 21 shows some examples applied to the rolling of thin hard materials. Smaller number of passes or good strip shape is expected under the low rolling force.

\section{Conclusion}

For the purpose of getting extremely high rolling reductions or decreasing the number of rolling mill stands, a new rolling mill named NGM has been developed.

This new type multi-reduction mill consists of three rolling gaps, and the strip is rolled by different roll speeds at each pass.

The results obtained by experimental tests and analytic calculations are as follows:

(1) The stable rolling of over $70 \%$ of the rolling reduction per one stand was obtained.

(2) The rolling force in NCM decreased from 30 
to $55 \%$ compared with that in the conventional one pass rolling.

(3) The consumption of the rolling energy in NCM was almost the same as that of the conventional rolling.

(4) The differences of the rolling characteristics between strip-pulling-out type and strip-enveloping type are little except the roll torque and the forward slip.

(5) In case of NCM, such optimum rolling condition can be realized by regulating the roll speed difference, that the inter-gap tensions can be moderate and slip ratios can be minimum.

(6) For the rolling of over $1.0 \mathrm{~mm}$ of the entry thickness, \#1 roll can be idle.

By using the experimental data, the designing for an actual production mill, in replace of three stands of tandem cold mill, has been carried out.

(7) For the rolling of thinner strip than $0.5 \mathrm{~mm}$ of the entry thickness, \#2 and \#3 rolls can be idle from analytical prediction.

This NCM is easily modified from the conventional 4-high or 6-high mill.

\section{REFERENCES}

1) M. Nakamura, S. Maki, S. Abe and N. Naoki: Proc. of the 1982 Japanese Spring Conference for Technology of Plasticity, Japan Soc. Technol. Plast., Tokyo, (1982), 77.

2) R. Terakado, T. Ooki, T. Iura, H. Hayashi, T. Ashiura, Y. Nishiyama and I. Takahashi: Proc. of the 34th Japanese Joint Conference for the Technology of Plasticity, Japan Soc. Technol. Plast., Tokyo, (1983), 209.

3) Machinery and Production Engineering, (1976), July 21, 64.

4) H. Shiozaki, S. Shinya, M. Mikami and S. Koide: Proc. of the 32nd Japanese Joint Conference for Technology of Plasticity, Japan Soc. Technol. Plast., Tokyo, (1981), 153.

5) H. Yamamoto, T. Shiraishi, H. Shiozaki, M. Mikami, A. Tanaka and M. Tsugeno: Proc. of the 36 th Japanese Joint Conference for Technology of Plasticity, Japan Soc. Technol. Plast., Tokyo, (1985), 89. 